\title{
Addressing the social causes of poor health is integral to practising good medicine
}

I am sitting one morning in the family medicine clinic direct viewing a resident conducting a routine follow-up of a six-month-old infant. The resident who is using the Rourke Baby Record diligently asks a series of questions, performs a thorough physical exam, and proceeds to check the little tick-boxes. He comes to the viewing room to review the case and gives an eloquent report of how well the boy is doing: growth curves following the 50th percentile, vaccines up to date, meeting the developmental milestones, eyes, ears and hips are normal. One might be inclined to sign off here and move onto the next patient, yet something is troubling. Where is the mother? While I'm all for equality of the sexes, and there is no reason why a father cannot bring in a child for a routine check-up, the entire interview did not include one question about the family's home life. How are the parents coping? Are there financial pressures? Do they have social support?

We know that rates of family violence are high across socioeconomic strata, and that there is a great deal of underreporting. According to a recent report, 1 in 16 Canadians is a victim of physical or sexual abuse, 1 in 6 is a victim of emotional or financial abuse, and less than a quarter report this to the police. ${ }^{1}$ What if the mother did not come to the clinic because she was ashamed to be seen with a black eye? The health of this child probably depends more on the health of the home environment than any other factor. The Rourke Baby Record recommends asking about family stress and assessing the need for home visitation - an evidencebased program that is proven to reduce rates of child abuse and neglect.

However, it is simply not in the medical mindset to pay as much attention to these "softer" social factors as opposed to the "hard facts" such as weight, height and red reflex. Indeed, even in medical school, there is a systems-based model for learning the profession: circulatory

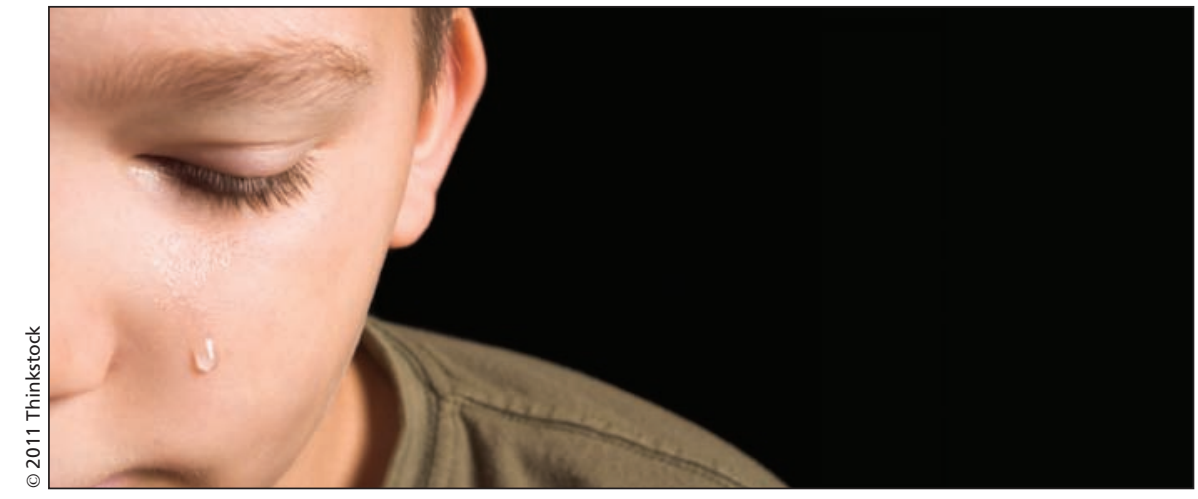

system, respiratory system, nervous system, and so forth. But what about the social system? Owing to the lack of a "social body part," there is no two-month block of teaching in most undergraduate medical curricula dedicated to the family, community and societal factors that influence health. Understanding and addressing the social determinants of health, including providing much-needed social support, is something that is often marginalized and relegated to family caregivers and community groups at the periphery of the formal health system.

During a postgraduate teaching session on social support, a resident proposed that a nurse should triage patients for social problems and refer them to a social worker before they see the doctor, so that the doctor can focus on dealing with physical complaints. Osler would be rolling in his grave to hear such blasphemy. Whatever happened to treating the whole patient and not just the disease?

It is time to be proactive about placing social issues at the heart of how we train the health professionals of tomorrow, instead of continuing to "put on band-aids" while the upstream causes of ill-health remain unaddressed. Not only is it unsustainable for the health system as costs continue to rise, but such reductionism also misses an important opportunity for prevention.

Indeed, physicians are not helpless when it comes to managing social problems. Enquiring about social issues is an important start — and it takes only a couple minutes. Referral to available social support systems including a plethora of community groups is also well within our capacities. Advocating to improve the health of patients and populations is yet another thing that we are well positioned to do. The CanMeds advocacy role is not just about getting patients their MRI or hip replacement faster. Advocacy is also needed at a higher level in support of public policies that aim to reduce poverty and social exclusion and to promote the rights of all Canadians. While many of the social factors that contribute to poor health and health inequities lie outside the health sector, health systems nonetheless can play an important role in promoting health equity. ${ }^{2}$ A first step is recognizing that that the adoption of a population health approach is important and that addressing the social causes of poor health is integral to practising good medicine.

\section{Anne Andermann MD DPhil \\ Faculty of Medicine \\ McGill University \\ Montréal, Que.}

\section{References}

1. Family violence in Canada: A statistical profile. Ottawa (ON): Statistics Canada; 2011. Cat. no. 85224-X

2. Van Lerberghe W, Evans T, Rasanathan K, et al. World health report 2008. Primary health care: Now more than ever. Geneva (Switzerland): World Health Organization; 2008. 